\section{ALICE CHEDID, MD}

Nephrology Fellow, Department

of Medicine, Division of Nephrology,

Johns Hopkins University, Baltimore, MD
MOHAMAD HANOUNEH, MD

Instructor of Medicine, Department

of Medicine, Division of Nephrology,

Johns Hopkins University, Baltimore, MD
C. JOHN SPERATI, MD, MHS

Associate Professor of Medicine, Department

of Medicine, Division of Nephrology,

Johns Hopkins University, Baltimore, MD

\title{
Renal vein thrombosis and pulmonary embolism
}

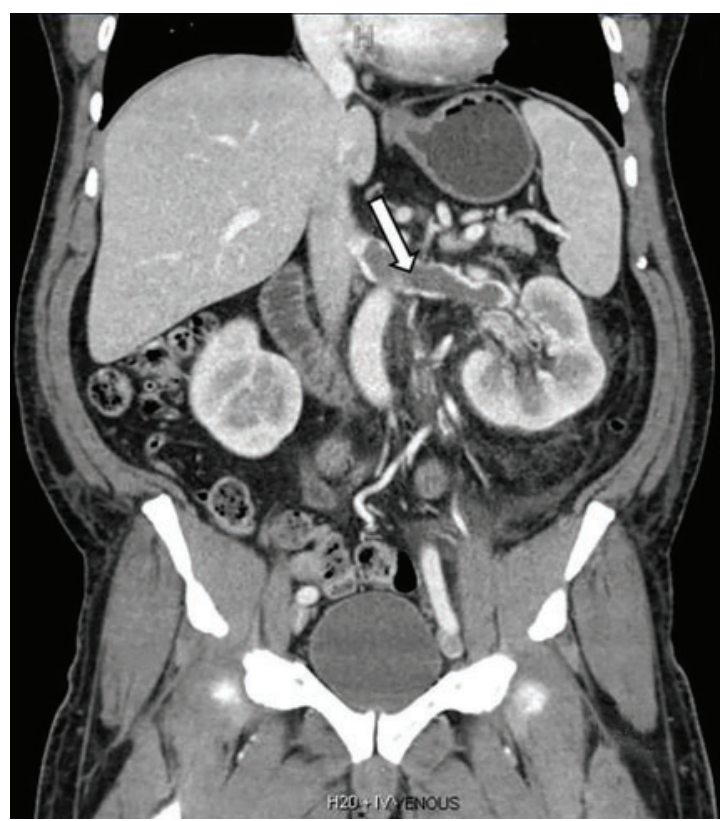

Figure 1. Coronal reformatted contrastenhanced computed tomography showed a nearly occlusive low-attenuation filling defect within the left renal vein (arrow).

A 49-YEAR-OLD MAN developed nephroticrange proteinuria (urine protein-creatinine ratio $4.1 \mathrm{~g} / \mathrm{g}$ ), and primary membranous nephropathy was diagnosed by kidney biopsy. He declined therapy apart from angiotensin receptor blockade.

Five months after undergoing the biopsy, he presented to the emergency room with marked dyspnea, cough, and epigastric discomfort. His blood pressure was 160/100 mm $\mathrm{Hg}$, heart rate 95 beats/minute, and oxygen saturation by pulse oximetry $97 \%$ at rest on ambient air, decreasing to $92 \%$ with ambulation.

doi:10.3949/ccjm.85a.18064

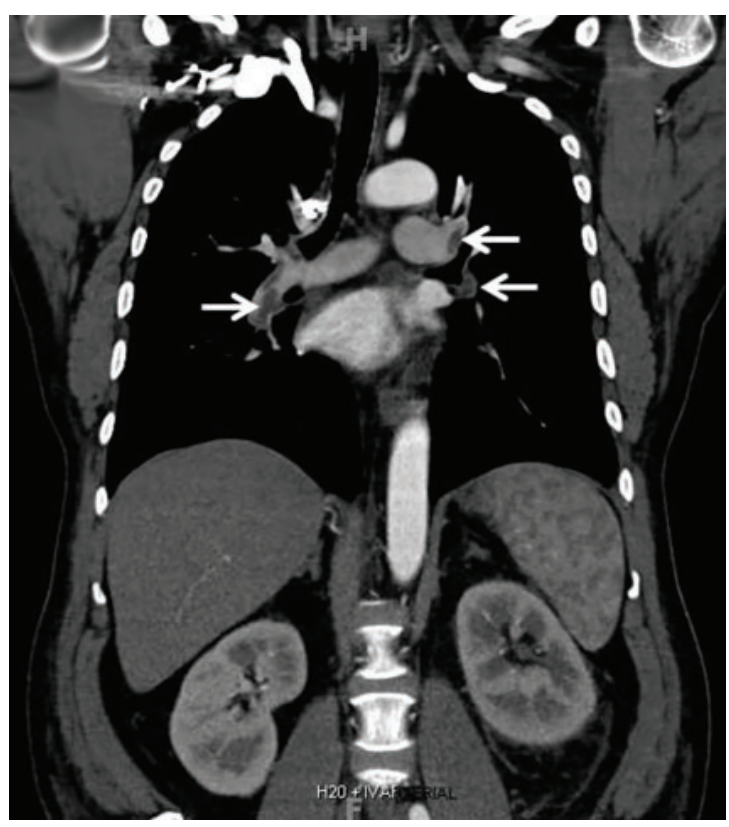

Figure 2. Coronal reformatted contrastenhanced computed tomography of the chest showed bilateral low-attenuation filling defects in the pulmonary arteries (arrows).

Initial laboratory testing results were as follows:

- Sodium $135 \mathrm{mmol} / \mathrm{L}$ (reference range 136144)

- Potassium $3.9 \mathrm{mmol} / \mathrm{L}(3.7-5.1)$

- Chloride $104 \mathrm{mmol} / \mathrm{L}$ (97-105)

- Bicarbonate $21 \mathrm{mmol} / \mathrm{L}(22-30)$

- Blood urea nitrogen 14 mg/dL (9-24)

- Serum creatinine $1.1 \mathrm{mg} / \mathrm{dL}(0.73-1.22)$

- Albumin $2.1 \mathrm{~g} / \mathrm{dL}$ (3.4-4.9).

Urinalysis revealed the following:

- 5 red blood cells per high-power field, compared with 1 to 2 previously

- 3+ proteinuria

- Urine protein-creatinine ratio $11 \mathrm{~g} / \mathrm{g}$

- No glucosuria.
A man with membranous nephropathy presented with dyspnea, cough, and epigastric discomfort 
Electrocardiography revealed normal sinus rhythm without ischemic changes. Chest radiography did not show consolidation.

Computed tomography of the chest and abdomen with intravenous contrast demonstrated a nearly occlusive thrombus in the left renal vein (Figure 1) extending to the inferior vena cava with bilateral, nearly occlusive pulmonary emboli (Figure 2).

The patient was started on systemic anticoagulation with unfractionated heparin, which was then transitioned to warfarin therapy. Immunosuppressive therapy was also started, with rituximab 1,000 mg every other week for 2 doses, and 6 months of alternating monthly oral therapy with cyclophosphamide and methylprednisolone.

At 7 months after the thrombotic event, there was no evidence of residual renal vein thrombosis on magnetic resonance venography, and at 14 months his serum creatinine level was $0.9 \mathrm{mg} / \mathrm{dL}$, albumin $4.0 \mathrm{~g} / \mathrm{dL}$, and urine protein-creatinine ratio $0.8 \mathrm{~g} / \mathrm{g}$.

\section{RENAL VEIN THROMBOSIS: RISK FACTORS AND CLINICAL FEATURES}

Severe hypoalbuminemia in the setting of nephrotic syndrome due to membranous nephropathy is associated with the highest risk of venous thromboembolic events, with renal vein thrombus being the classic complica- tion. ${ }^{1}$ Venous thromboembolic events also occur in other nephrotic syndromes, albeit at a lower frequency. ${ }^{2}$

Venous thromboembolic events are estimated to occur in $7 \%$ to $33 \%$ of patients with membranous glomerulopathy, with albumin levels less than $2.8 \mathrm{~g} / \mathrm{dL}$ considered a notable risk factor. ${ }^{1,2}$

While often a chronic complication, acute renal vein thrombosis may present with flank pain and hematuria. ${ }^{3}$ In our patient, the dramatic increase in proteinuria and possibly the increase in hematuria suggested renal vein thrombosis. Proximal tubular dysfunction, such as glucosuria, can be seen on occasion.

\section{DIAGNOSIS AND TREATMENT}

Screening asymptomatic patients for renal vein thrombosis is not recommended, and the decision to start prophylactic anticoagulation must be individualized. ${ }^{4}$

Although renal venography historically was the gold standard test to diagnose renal vein thrombosis, it has been replaced by noninvasive imaging such as computed tomography and magnetic resonance venography.

While anticoagulation remains the treatment of choice, catheter-directed thrombectomy or surgical thrombectomy can be considered for some patients with acute renal vein thrombosis. ${ }^{5}$

\section{REFERENCES}

1. Couser WG. Primary membranous nephropathy. Clin J Am Soc Nephrol 2017; 12(6):983-997. doi:10.2215/CJN.11761116

2. Barbour SJ, Greenwald A, Djurdjev O, et al. Disease-specific risk of venous thromboembolic events is increased in idiopathic glomerulonephritis. Kidney Int 2012; 81(2):190-195. doi:10.1038/ki.2011.312

3. Lionaki S, Derebail VK, Hogan SL, et al. Venous thromboembolism in patients with membranous nephropathy. Clin J Am Soc Nephrol 2012; 7(1):43-51. doi:10.2215/CJN.04250511

4. Lee T, Biddle AK, Lionaki S, et al. Personalized prophylactic antico- agulation decision analysis in patients with membranous nephropathy. Kidney Int 2014; 85(6):1412-1420. doi:10.1038/ki.2013.476

5. Jaar BG, Kim HS, Samaniego MD, Lund GB, Atta MG. Percutaneous mechanical thrombectomy: a new approach in the treatment of acute renal-vein thrombosis. Nephrol Dial Transplant 2002; 17(6):1122-1125. pmid:12032209

ADDRESS: Mohamad Hanouneh, MD, Department of Medicine, Division of Nephrology, Johns Hopkins University, 1830 E Monument Street, Room 416, Baltimore, MD 21287; Mhanoun1@jhmi.edu 